PAPER

\title{
Neuropsychological profile of young adults with spina bifida with or without hydrocephalus
}

\author{
J L Iddon, D J R Morgan, C Loveday, B J Sahakian, J D Pickard
}

J Neurol Neurosurg Psychiatry 2004;75:1112-1118. doi: 10.1136/jnnp.2003.029058

See end of article for authors' affiliations

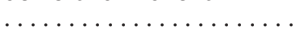

Correspondence to: Dr J L Iddon, Department of Academic

Neurosurgery, Box 167, University of Cambridge, Addenbrooke's Hospital, Hills Road, Cambridge, CB2 5RG, UK; joiddon@ aol.com

Received

24 September 2003

In revised form

29 December 2003

Accepted 16 January 2004
Objectives: To determine the relative impact of hydrocephalus and spinal dysraphism in young adults on intellectual and cognitive functioning. Sub-groups of patients with congenital hydrocephalus and/or spina bifida were assessed between 1995 and 2003. The entry criteria were that individuals should have (i) intact global function, (ii) average verbal intelligence (or above), and (iii) should not have clinical depression. There were three sub-groups: patients with hydrocephalus and spina bifida, patients with hydrocephalus without spina bifida, and patients with spina bifida without hydrocephalus.

Methods: Patients were neuropsychologically assessed as part of their normal clinical assessment during their annual medical review. Each individual completed a screening battery assessing global functioning, verbal intelligence, and mood. In addition they completed additional tests including measures of emotional intelligence, memory, attention, and executive function. Results were analysed to compare the performance of the patient sub-groups and to compare them to a healthy control group.

Results: Patients with hydrocephalus (with or without spina bifida) were significantly impaired on the vast majority of all test scores as compared to patients with spina bifida and healthy controls. They were particularly poor on measures assessing executive function. By contrast for patients with spina bifida with no associated hydrocephalus, the significant majority of all test scores fell within the average range or above.

Conclusions: The neuropsychological profile of patients with hydrocephalus is one of relative impairment and this is so whether or not spina bifida is present. In spina bifida alone, in the absence of hydrocephalus, cognitive function is relatively spared.
$\mathrm{T}$ he studies of cognitive function in patients with hydrocephalus have primarily been carried out in children. The general consensus is that overall such subjects have reduced cognitive functioning compared to healthy children, ${ }^{1-5}$ particularly with regard to poor attention and high distractibility, ${ }^{6}{ }^{7}$ impaired memory, possibly associated with poor strategy, ${ }^{8}$ reduced language skills, ${ }^{6-14}$ and finally maths, numeracy, and problem solving difficulties. ${ }^{15} 16$ In a post-hoc analysis of a group of 115 patients out of 233 children with hydrocephalus who had undergone a shunt operation between 1964 and 1984, Lumenta and Skotarczak ${ }^{17}$ reported that the majority had no cognitive deficits $(63 \%)$ but the remainder $(37 \%)$ showed problems with memory and concentration, reduced intellectual ability, and decreased performance in school.

There are many factors which complicate the interpretation of cognitive test results in congenital or early acquired hydrocephalus. The patient group is heterogeneous with a wide variety of causes (prematurity, meningitis, haemorrhage, spinal dysraphism, Dandy-Walker syndrome, tuberous sclerosis, Meckel syndrome, Smith-Lemli-Opitz syndrome, etc) and varying degrees of physical disability. There is a high incidence of epilepsy (40\%), albeit usually mild. Medications and approaches to treatment vary, for example, some patients are shunted (using a wide variety of devices) very early on, whilst others appear to "arrest" spontaneously, but remain at risk of sudden and sometimes lethal deterioration, and there has also been a resurgence of enthusiasm for third ventriculostomy to try and avoid shunting.

The impact of the high incidence of concomitant spina bifida (approximately $80 \%$ ) has not been adequately studied. A number of studies refer only to spina bifida but do not define how many of the subjects also had hydrocephalus. Several studies have reported cognitive dysfunction in children and young adults with spina bifida, ${ }^{78-21}$ whereas other authors suggest that children with spina bifida score closer to the "normal" range on cognitive tests. ${ }^{8}$ There does not appear to be a clear consensus from the published studies whether hydrocephalus and/or spina bifida is the main cause of any cognitive dysfunction. Clearly hydrocephalus as a brain disorder, sometimes accompanied by other abnormalities such as agenesis of the corpus callosum and delayed myelination, is more likely to be the cause of cognitive dysfunction than spinal dysraphism affecting the lumbar spine. However, the latter may be accompanied by low selfesteem due to the physical disability, which may impact on education and subsequent intellectual and cognitive function. ${ }^{22-25}$

Any study that seeks to compare the neuropsychological profiles of different patient groups must control for intelligence. Although the majority of young subjects with hydrocephalus have measurably average intelligence, there are subgroups with mild or moderate learning disability and others with high average IQ or above. Hagberg ${ }^{26}$ found that lower IQ and neurological abnormalities were particularly associated with behavioural problems. Other studies have tended to report generally about intelligence in hydrocephalus without dividing the patients into sub-groups. For instance, there have been reports of reduced performance IQ scores, for example on tests of reasoning and comprehension, ${ }^{11}$ and poor visuospatial and perceptual skills, ${ }^{72}$ but in the presence of preserved performance on verbal intelligence tasks. ${ }^{28}$ In contrast, Ingram and Naughton ${ }^{9}$ and Simpson and Hemmer $^{29}$ have reported intelligence to be in the "normal" range in the majority of individuals with hydrocephalus and

Abbreviations: $\mathrm{NPH}$, normal pressure hydrocephalus 
that this is not a factor in causing overt intellectual disabilities or consequent handicap in school or employment.

Older adults with acquired "normal pressure" hydrocephalus (NPH) show a similar pattern of cognitive impairment to that reported for children with hydrocephalus, namely difficulties with memory, which often improve postshunt, ${ }^{30-33}$ and frontal lobe executive functioning, which does not seem to benefit from shunting. ${ }^{34-39}$ It is difficult to make direct comparisons about profiles of cognitive dysfunction because NPH patients are much older and may have other comorbidity such as hypertension, small cerebral vessel disease, and Alzheimer's disease.

The main aim of the present study was to clarify, using a broad range of sensitive cognitive tasks, what cognitive difficulties patients with congenital hydrocephalus and/or spina bifida have once they reach adult life. Only patients with verbal intelligence in the average range or above were included to avoid difficulties of interpretation due to low IQ or learning disability. Individuals with significant depression were also excluded as mood disorder itself causes cognitive dysfunction. Three patient groups were included: patients with hydrocephalus and spina bifida, patients with hydrocephalus without spina bifida, and patients with spina bifida without hydrocephalus. A healthy control group was also included for comparisons with the normal population.

\section{METHODS \\ Patients}

Patients completed a brief neuropsychological test battery together with as many cognitive tests as there was time for as part of their routine clinical assessment between 1995 and 2003 in two tertiary referral centres: (i) at the Chelsea and Westminster Hospital in London at a specialist hydrocephalus and spina bifida day clinic $^{40}$ medically overseen by a consultant physician (DJRM) and (ii) at Addenbrooke's Hospital in Cambridge overseen by a consultant neurosurgeon (JDP). All patients were diagnosed with hydrocephalus, which was either congenital or acquired soon after birth. All hydrocephalus patients included had undergone shunt surgery at an early age (ventriculoperitoneal or ventriculotrial shunting using either a Medos-Programmable or Delta level 1 valve). All patients were assessed by the principal psychologist (JLI) or by a supervised research assistant. Patients were excluded on the following basis: intelligence score under 90, scoring below cut off on the global screening measure, partial sight, or significant depression.

For the majority of the tests patients were divided into three main groups: group 1 individuals with hydrocephalus and spina bifida, group 2 individuals with hydrocephalus alone (that is, no concomitant spina bifida), and group 3 individuals with spina bifida alone (that is, no concomitant hydrocephalus). On three tests (Hopkins, Trails, and the Eyes Test, see below) there were not enough data in each group to warrant separate sub-group comparisons and only two groups were compared-group l patients with hydrocephalus with or without spina bifida and group 2 patients with spina bifida alone.

As well as sub-group comparisons the patient groups were also compared to an age and intelligence matched healthy control group. These controls were screened for neurological and psychiatric disorders and came from the Cambridge area. For some tests only normative databases were available and in these cases comparisons were made and the proportion of scores in the normal range documented.

\section{Neuropsychological testing}

Each patient completed a battery of screening tests to assess verbal intelligence, mood, and level of global functioning. Estimated verbal intelligence (IQ) was measured using the
National Adult Reading Test ${ }^{41}$-patients were excluded if they scored less than 90 (that is, below average). Mood and depression were screened for using the Beck Depression Inventory ${ }^{42}$-patients were excluded if they scored in the moderately depressed range or above. The Mini Mental State Examination $^{43}$ was used as a general cognitive screening measure-patients were excluded if they scored below 27.

In addition, following the administration of the standard screening battery a further battery of cognitive tests was administered to each person, in a randomised order. Due to lack of time, not all patients were able to complete every test. The test sessions took place in a quiet, private room in the hospital. Some of the tests were paper and pencil based and some were computerised and included tasks assessing a broad range of cognitive functions. These have been described in detail elsewhere but a brief description and reference are provided here.

The Eyes Test of Emotional Judgment/Intelligence has previously been shown to be impaired in individuals with autism. ${ }^{44}$ Verbal and Semantic Fluency ${ }^{45}$ evaluates the spontaneous production of words beginning with a given letter or from a specific semantic category within a limited amount of time. The CANTAB tests assess visual and spatial recognition memory, ${ }^{46} 47$ spatial memory span, ${ }^{48}{ }^{51}$ spatial working memory and strategy ${ }^{50}$ and attentional set-shifting (including rule learning and cognitive flexibility). ${ }^{49}{ }^{50}$ The Trails A and B Tests ${ }^{51}$ assess attention, sequencing, mental flexibility, visual search, and motor function and the Hopkins Verbal Learning Test $^{52}$ assesses immediate verbal recall, learning, recognition memory, and delayed memory recall (including measures of strategy and intrusion error).

\section{RESULTS}

Analysis of variance was performed using Statview to compare patient sub-groups and the matched control group. If there was a significant effect of group, pairwise comparisons were made using Fisher's test. Where control data were not available, unpaired $t$ tests were used to compare the hydrocephalus and spina bifida groups (for Hopkins and Trails Tests) and data were compared to a normative control database (percentages are reported).

Group numbers, means, and standard deviations of all cognitive tasks are displayed in table 1. Means and standard errors of specific test scores are depicted in figs 1-7. Results are detailed below. In summary, there was no significant difference between any of the groups on the Eyes Test of Emotional Judgement. On all other cognitive test measures, there was no significant difference between the two hydrocephalus sub-groups, but both sub-groups were significantly impaired compared to patients with spina bifida without hydrocephalus (with the exception of performance on the CANTAB Visual Recognition Memory task and on the CANTAB Spatial Working Memory strategy score) and across the board when compared to healthy controls. By contrast, there was no significant difference on the majority of the test measures between the spina bifida alone and healthy control group, with the exception of the semantic fluency task where the spina bifida group generated fewer words. However, it should be noted that all individual test scores of the spina bifida alone group fell within the normal range according to the normative database, and they were significantly better when compared to the hydrocephalus sub-groups.

\section{Summary of test results}

Normal range is defined as a low average performance or above (that is 10th percentile or above).

The Eyes Test of Emotional Judgment

Contrast all groups $\mathrm{F}=2.86, \mathrm{p}=0.062$. 


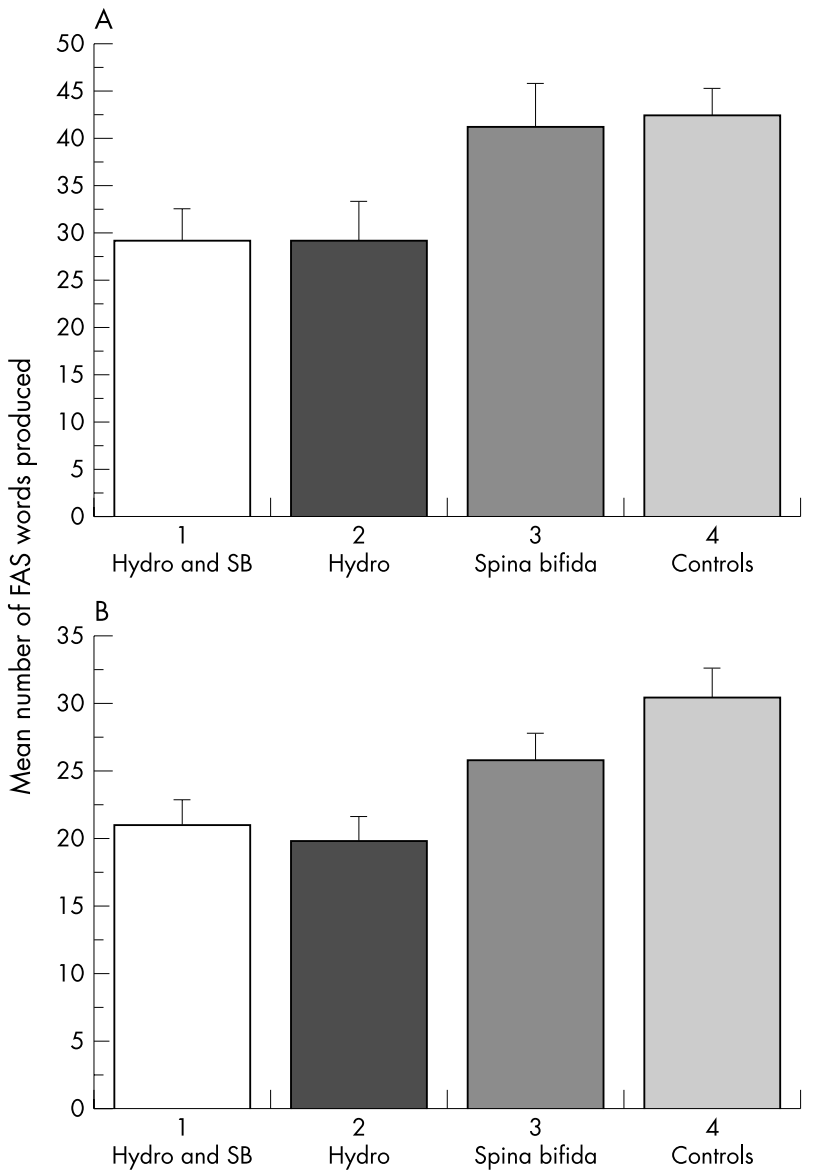

Figure 1 (A) Verbal fluency; (B) semantic fluency.

\section{Verbal Fluency}

Contrast all groups $\mathrm{F}=21.4, \mathrm{p}<0.01$. Sub-group contrasts hydrocephalus (hydro) and spina bifida (SB) $v$ hydro alone $\mathrm{p}=0.76, v$ SB alone $\mathrm{p}<0.01$, and $v$ controls $\mathrm{p}<0.01$. Hydro alone $v$ SB $\mathrm{p}<0.01$ and $v$ controls $\mathrm{p}<0.01$. SB $v$ controls $\mathrm{p}=0.56$.

\section{Semantic Fluency}

Contrast all groups $\mathrm{F}=25.3, \mathrm{p}<0.01$. Sub-group contrasts hydro and SB $v$ hydro alone $\mathrm{p}=0.53, v$ SB alone $\mathrm{p}<0.01$, and $v$ controls $\mathrm{p}<0.01$. Hydro alone $v$ SB $\mathrm{p}<0.01$ and $v$ controls $\mathrm{p}<0.01$. SB $v$ controls $\mathrm{p}<0.01$.

\section{CANTAB Visual Recognition Memory test}

Contrast all groups $\mathrm{F}=5.6, \mathrm{p}<0.01$. Sub-group contrasts hydro and SB $v$ hydro alone $\mathrm{p}=0.39, v$ SB alone $\mathrm{p}=0.053$, and $v$ controls $\mathrm{p}<0.01$. Hydro alone $v$ SB $\mathrm{p}<0.05$ and $v$ controls $\mathrm{p}<0.01$. SB $v$ controls $\mathrm{p}=0.87$.

\section{CANTAB Spatial Recognition Memory test}

Contrast all groups $\mathrm{F}=15.5, \mathrm{p}<0.01$. Sub-group contrasts hydro and SB $v$ hydro alone $\mathrm{p}=0.43, v$ SB alone $\mathrm{p}<0.01$, and $v$ controls $\mathrm{p}<0.01$. Hydro alone $v$ SB $\mathrm{p}<0.01$ and $v$ controls $\mathrm{p}<0.01$. SB $v$ controls $\mathrm{p}=0.31$.

\section{CANTAB Spatial Memory Span}

Contrast all groups $F=14.7, p<0.01$. Sub-group contrasts hydro and SB $v$ hydro alone $\mathrm{p}=0.16, v$ SB alone $\mathrm{p}<0.05$, and $v$ controls $\mathrm{p}<0.01$. Hydro alone $v \mathrm{SB} \mathrm{p}=0.15$ and $v$ controls $\mathrm{p}<0.01$. SB $v$ controls $\mathrm{p}=0.07$.
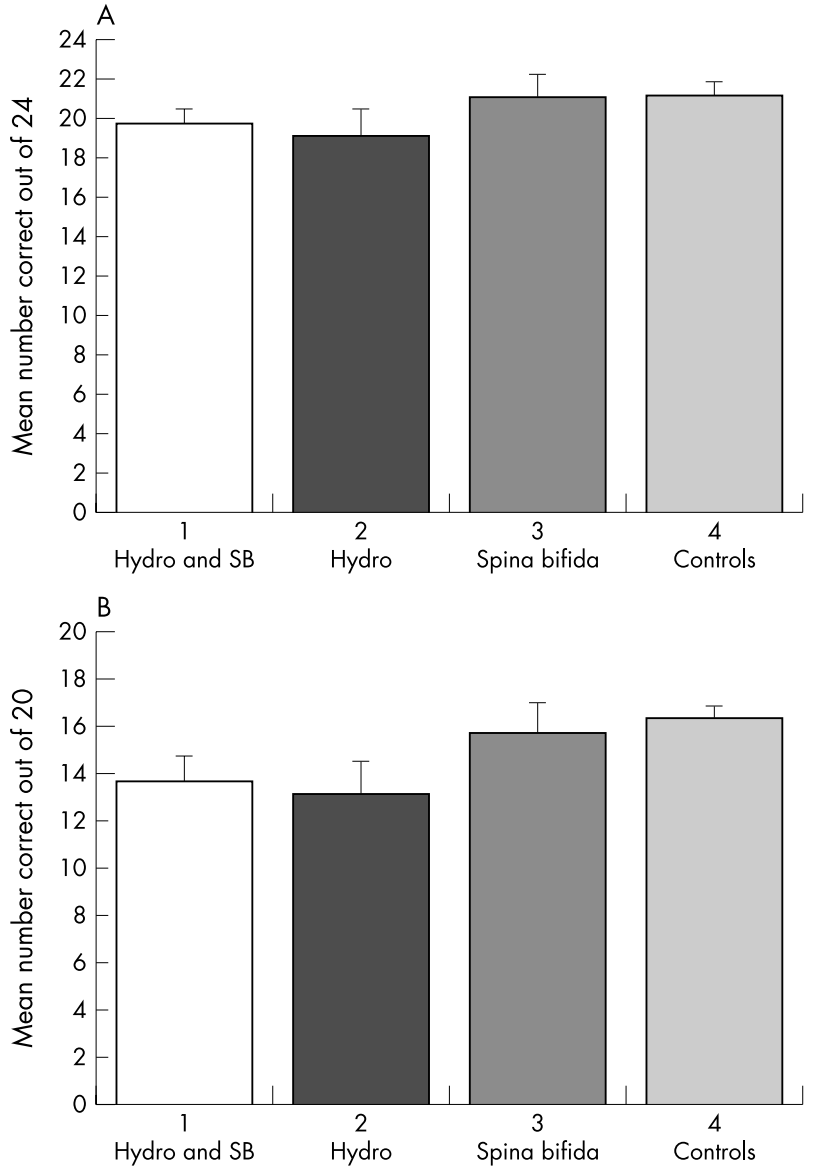

Figure 2 (A) Pattern recognition memory; (B) spatial recognition memory.

\section{CANTAB Spatial Working Memory errors}

Contrast all groups $\mathrm{F}=16.1, \mathrm{p}<0.01$. Sub-group contrasts hydro and SB $v$ hydro alone $\mathrm{p}=0.89, v$ SB alone $\mathrm{p}<0.01$, and $v$ controls $\mathrm{p}<0.01$. Hydro alone $v \mathrm{SB} \mathrm{p}<0.01$ and $v$ controls $\mathrm{p}<0.01$. SB $v$ controls $\mathrm{p}=0.36$.

\section{CANTAB Spatial Working Memory strategy}

Contrast all groups $\mathrm{F}=2.77, \mathrm{p}<0.05$. Sub-group contrasts hydro and SB $v$ hydro alone $\mathrm{p}=0.69, v$ SB alone $\mathrm{p}=0.07$, and $v$ controls $\mathrm{p}<0.05$. Hydro alone $v \mathrm{SB} \mathrm{p}<0.05$ and $v$ controls $\mathrm{p}<0.05$. SB $v$ controls $\mathrm{p}=0.60$.

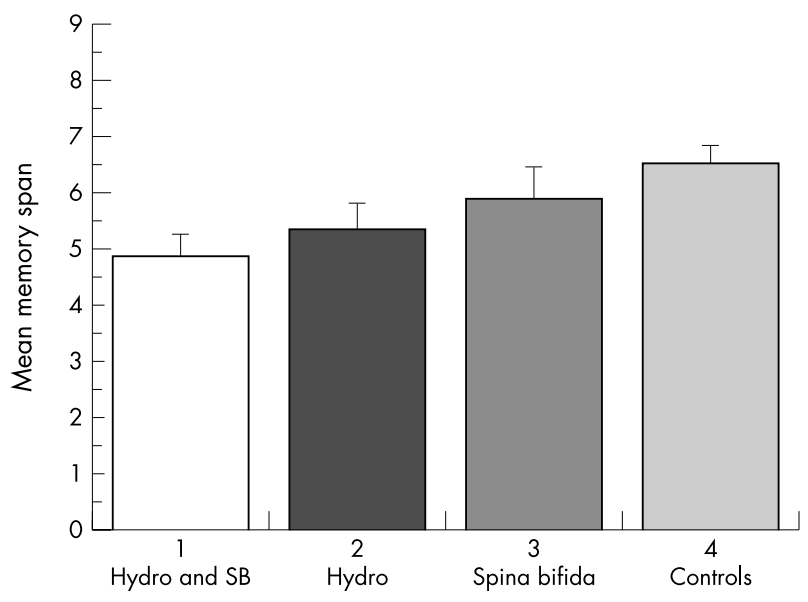

Figure 3 Spatial memory span. 


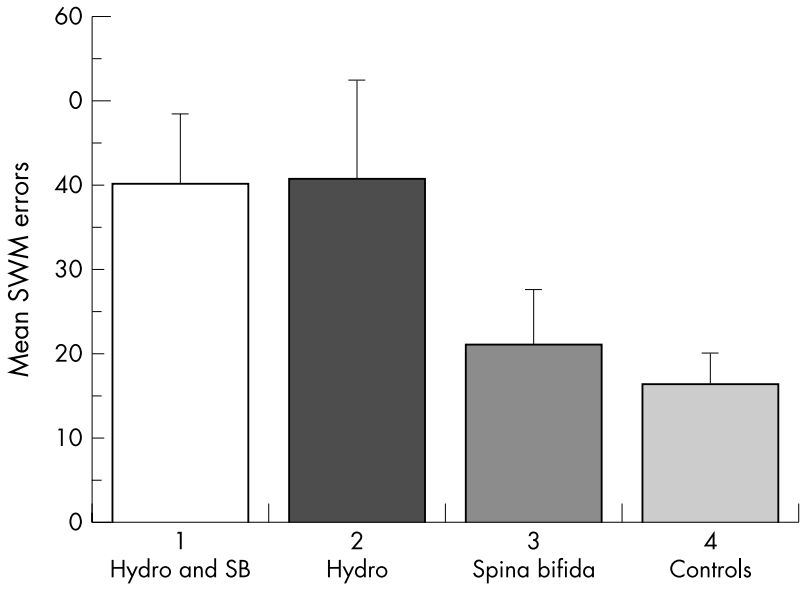

Figure 4 Spatial working memory errors.

\section{Attentional Set-Shifting (total errors)}

Contrast all groups $\mathrm{F}=18.5, \mathrm{p}<0.01$. Sub-group contrasts hydro and SB $v$ hydro alone $\mathrm{p}=0.61, v$ SB alone $\mathrm{p}<0.01$, and $v$ controls $\mathrm{p}<0.01$. Hydro alone $v \mathrm{SB} \mathrm{p}<0.01$ and $v$ controls $\mathrm{p}<0.01$. SB $v$ controls $\mathrm{p}=0.80$.

\section{The Trails A test}

Contrast all groups $\mathrm{F}=4.79, \mathrm{p}<0.05$. Hydro $65 \%$ in normal range, SB $100 \%$ in normal range.

\section{The Trails B test}

Contrast all groups $\mathrm{F}=9.11, \mathrm{p}<0.01$. Hydro $39 \%$ in normal range, SB $92 \%$ in normal range.

\section{Hopkins Immediate Recall}

Contrast all groups $\mathrm{F}=19.7, \mathrm{p}<0.01$. Hydro $83 \%$ in normal range, SB $100 \%$ in normal range.

\section{Hopkins total three-trial learning}

Contrast all groups $\mathrm{F}=19.46, \mathrm{p}<0.01$. Hydro $31 \%$ in normal range, $\mathrm{SB} 100 \%$ in normal range.

\section{Hopkins Recognition Memory}

Contrast all groups $\mathrm{F}=5.37, \mathrm{p}<0.05$. Hydro $95 \%$ in normal range, SB $100 \%$ in normal range.

\section{Hopkins Delayed Recall}

Contrast all groups $\mathrm{F}=8.28, \mathrm{p}<0.01$. Hydro $34 \%$ in normal range, SB $83 \%$ in normal range.

\section{Hopkins strategy score}

Contrast all groups $\mathrm{F}=21.7, \mathrm{p}<0.01$.

\section{Hopkins intrusion errors}

Contrasts all groups $\mathrm{F}=6.60, \mathrm{p}<0.05$.

\section{DISCUSSION}

In this study, sub-groups of patients with hydrocephalus and/ or spina bifida were compared. These groups were compared to a matched healthy control group and/or to normative databases. It was clear from the group analysis that, while patients with hydrocephalus (with or without spina bifida) appeared to be normally intelligent on a traditional measure of verbal IQ, with normal emotional intelligence, as a group they showed a global pattern of impairment on all other tasks as compared to patients with spina bifida and matched controls.

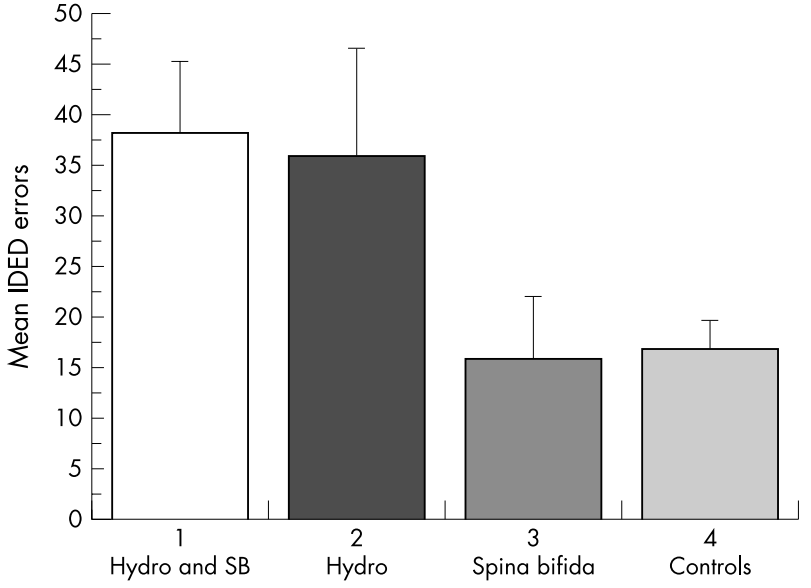

Figure 5 Attentional set-shifting task.

Overall the hydrocephalus groups had a high spread of scores, which were not normally distributed, with significantly more scores falling within the low average range or below. Neuropsychological assessment and cognitive profiling in hydrocephalus can start to explain the anecdotal difficulties reported by individuals and their relatives against the background of preserved intellectual and social functioning. In contrast, individuals with spina bifida without associated hydrocephalus overall do not appear to demonstrate significant cognitive impairment, although issues around physical disability and self-esteem are potentially confounding factors and may account for some of the outliers in this group. Several studies have highlighted these complicating factors when assessing behaviour and selfconfidence in relation to $\mathrm{SB},{ }^{22}{ }^{53-55}$ although in contrast, other studies have reported no significant difference on measures of self-confidence and global worth in individuals with SB. ${ }^{5657}$ Certainly the results of this study and in this particular group of individuals with spina bifida, suggest that although self-confidence issues may be important, they do not seem to be associated with significant cognitive dysfunction. Overall we have found that patients with spina bifida follow a fairly normal distribution in terms of their test scores. In addition they do not have the same difficulties in life as individuals with hydrocephalus and are often high achievers.

Close inspection of the data suggests that there are some types of function which are impaired in the majority of

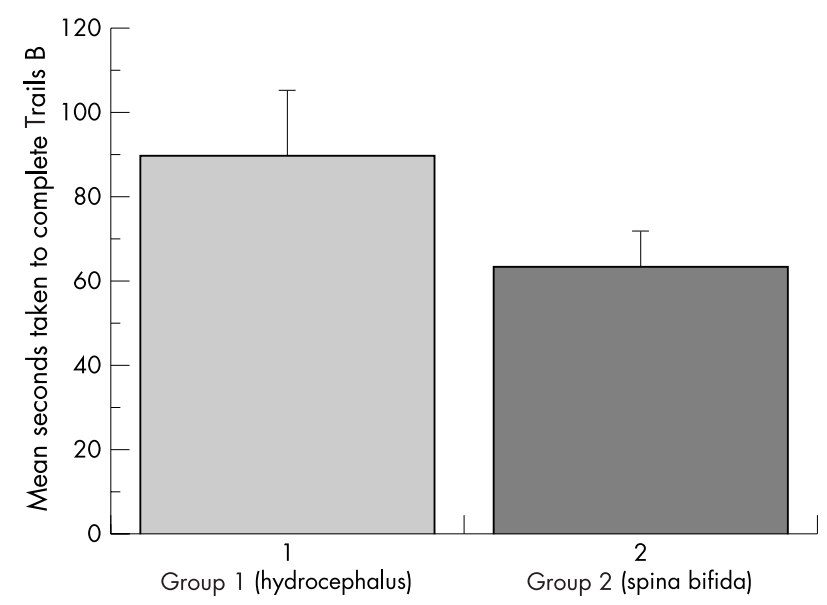

Figure 6 Trails B sequencing. 

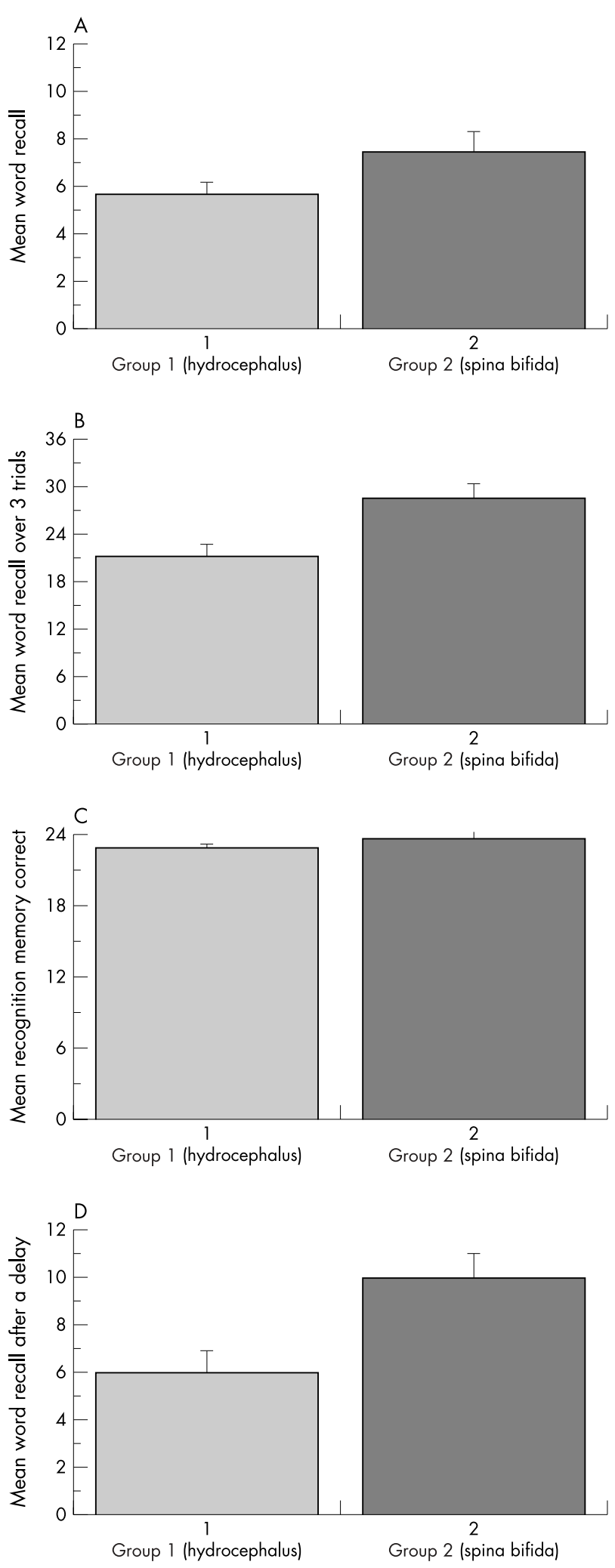

Figure 7 (A) Hopkins Immediate Recall; (B) Hopkins Learning; (C) Hopkins Recognition Memory; (D) Hopkins Delayed Memory Recall.

individuals with hydrocephalus and other types of function which are only impaired in a few. So for example, there were many more average scores or above on tests of semantic fluency $(81 \%)$, verbal recognition memory $(66 \%)$, spatial memory span $(77 \%)$, and visual recognition memory $(60 \%)$.
By contrast hydrocephalus patients showed a much lower distribution of scores with the majority in the low average range or below on tests of verbal learning ability (73\%), delayed verbal recall $(81 \%)$, spatial working memory $(73 \%)$, attentional set-shifting (63\%), and psychomotor speed on complex tasks involving sequencing (64\%). On tests of immediate verbal recall, spatial recognition memory, and simple measures of psychomotor speed approximately 50\% scored in the average range or above and 50\% scored in the low average range or below. This is compared to individuals with SB where the significant majority of all test scores fell within the average range or above. This profile suggests that individuals with hydrocephalus, with "normal" intelligence, show impairment on a broad range of tests but show a tendency towards a greater profile of impairment on tests of delayed memory, learning, and tests requiring a high level of attention, that is, tests of executive function (for example, spatial working memory, attentional set-shifting, sequencing, and cognitive flexibility). Subjects with hydrocephalus perform particularly poorly on tests requiring the integration of different cognitive processes, probably associated with attentional dysfunction (also highlighted by monitoring and intrusion errors), inflexibility of thought, and a lack of ability to improve performance via the use of strategies. These results suggest a core pattern of neural damage and resultant "executive" cognitive impairment, in the presence of preserved traditional and emotional intelligence and relatively preserved function on less effortful tasks (for example, recognition memory, memory span). It would be valuable to collect MRI data in these groups so that the functional data could be set against a structural background.

This study suggests that the cognitive impairment seen in hydrocephalus in childhood, ${ }^{2-5}$ including poor attention, ${ }^{67}$ memory problems, associated with poor strategy ${ }^{8}$ and poor language skills ${ }^{6-14}$ persists into adult life. Indeed it is probably when these individuals reach adulthood and try to lead a more independent life and seek employment, that the true extent of their cognitive difficulties emerges and becomes a significant problem. This will result in many difficulties within the workplace, for example, particularly in busy jobs where multi-tasking may be necessary and complex tasks need to be carried out. We acknowledge that this is not the case for all individuals with hydrocephalus but it is likely to be true for the majority. The percentage of individuals with hydrocephalus suffering from cognitive dysfunction in this study is somewhat higher, particularly in some areas of function as compared to other areas (as described above), than that reported by Lumenta and Skotarczak. ${ }^{17}$ This may be due to a variety of factors including differences in the selection of patients and the sensitivity of tests used.

These results suggest that individuals with congenital or early acquired hydrocephalus follow a pattern of cognitive dysfunction similar to that of high functioning individuals with acquired normal pressure hydrocephalus, ${ }^{34}$ at least on tests of executive function, which both groups completed. Iddon $e t a^{34}$ proposed a build up of CSF fluid caused dysfunction of the frontal lobes and associated sub-cortical neural circuitry (also see Fishman ${ }^{58}$ ). Failure to treat normal pressure hydrocephalus may lead to significant and global dementia, which can then only be partially relieved by shunting. Early in the course of the disorder, cognitive impairment is predominantly fronto-subcortical, but later becomes more global. Cognitive dysfunction may be more widespread in congenital hydrocephalus than is the case with normal pressure hydrocephalus. This may be because adults with acquired hydrocephalus have functioned normally and then lost function, whereas those with congenital hydrocephalus have never developed normal cognitive function. The damage is likely to be caused early on, probably before 
Table 1 Tests of cognitive function: group scores (standard deviation in brackets)

\begin{tabular}{|c|c|c|c|c|}
\hline Task & Hydro/SB & Hydro & SB & Controls \\
\hline Eyes Test of Emotional Judgement, $n$ & 47 & - & 18 & 50 \\
\hline Mean age & $26.8(6.1)$ & - & $30.4(9.6)$ & 30.1 (7.9) \\
\hline Mean NART IQ & $107.9(8.6)$ & - & $107.7(9.8)$ & $113.4(4.1)$ \\
\hline Mean eyes test score $(\max 25)$ & $19.8(2.9)$ & - & $19.8(2.8)$ & $19.8(2.1)$ \\
\hline Visual and Spatial Recognition Memory, $\mathrm{n}$ & 46 & 27 & 19 & 67 \\
\hline Mean age & $26.8(6.7)$ & $30.5(8.6)$ & $27.6(8.2)$ & $29.9(10.4)$ \\
\hline Mean NART IQ & $109.2(10.1)$ & $110.0(9.2)$ & $111.1(7.3)$ & $108.7(6.8)$ \\
\hline Mean visual recognition score ( $\max 24)$ & $19.7(2.7)$ & $19.2(3.4)$ & $21.2(2.3)$ & $21.3(2.4)$ \\
\hline Mean spatial recognition score $(\max 20)$ & $13.7(2.8)$ & $13.2(3.3)$ & $15.7(2.7)$ & $16.4(2.0)$ \\
\hline Spatial Memory Span, $\mathrm{n}$ & 39 & 26 & 19 & 67 \\
\hline Mean age & $27.3(7.1)$ & $30.1(8.5)$ & $26.4(6.9)$ & $30.2(10.0)$ \\
\hline Mean NART IQ & $109.4(9.7)$ & $109.4(9.4)$ & $110.9(8.5)$ & $110.5(7.4)$ \\
\hline Mean spatial span score $(\max 9)$ & $4.9(1.0)$ & $5.3(1.1)$ & $5.9(1.2)$ & $6.5(1.5)$ \\
\hline Spatial Working Memory ${ }^{*}, \mathrm{n}$ & 30 & 19 & 15 & 67 \\
\hline Mean age & $27.2(7.5)$ & $28.8(7.4)$ & $26.9(7.0)$ & $29.1(8.6)$ \\
\hline Mean NART IQ & $109.3(9.9)$ & $109.5(9.3)$ & $111.9(8.3)$ & $111.2(8.8)$ \\
\hline Mean spatial working memory errors & $39.9(22.5)$ & 40.7 (24.5) & $21.0(11.9)$ & $16.1(15.9)$ \\
\hline Mean spatial working memory strategy & $33.4(6.4)$ & $34.2(6.9)$ & $29.7(6.6)$ & $30.7(6.0)$ \\
\hline IDED Attentional Set-Shifting/Cognitive Flexibility Task, n & 37 & 18 & 16 & 72 \\
\hline Mean age & $26.5(7.1)$ & $29.6(8.0)$ & $27.6(6.4)$ & $29.2(8.6)$ \\
\hline Mean NART IQ & $108.8(9.7)$ & $109.7(10.1)$ & $112.5(6.9)$ & $111.6(8.6)$ \\
\hline Mean total error score & $38.2(21.6)$ & $35.8(21.5)$ & $15.9(11.6)$ & $17.0(11.8)$ \\
\hline Verbal (FAS) and Semantic (animals) Fluency, $n$ & 52 & 33 & 26 & 67 \\
\hline Mean age & $28.3(8.2)$ & $28.7(8.5)$ & $29.3(8.3)$ & $29.6(9.0)$ \\
\hline Mean NART IQ & $107.8(9.8)$ & $107.1(10.0)$ & $111.5(6.7)$ & $110.9(8.3)$ \\
\hline Mean FAS words produced & $29.0(10.0)$ & $29.8(10.7)$ & $41.2(11.1)$ & $42.7(11.4)$ \\
\hline Mean animals produced & $20.9(5.6)$ & $20.0(4.7)$ & $25.8(4.9)$ & $30.5(8.6)$ \\
\hline Hopkins Verbal Memory and Learning, $n$ & 51 & - & 21 & Control database \\
\hline Mean age & $30.6(8.9)$ & - & $33.3(12.1)$ & \\
\hline Mean NART IQ & $103.9(8.0)$ & - & $106.7(8.4)$ & \\
\hline Mean immediate recall score $(\max 12)$ & $5.7(1.4)$ & - & $7.2(1.3)$ & Average score 6-8 \\
\hline Mean 3-trial total learning score $(\max 36)$ & $21.7(3.9)$ & - & $26.5(4.7)$ & Average score $25-32$ \\
\hline Mean recognition memory score $(\max 24)$ & $23.1(1.0)$ & - & $23.6(0.7)$ & Average score $23-24$ \\
\hline Mean delayed recall score (max 12 ) & $6.6(3.7)$ & - & $9.7(1.8)$ & Average score 9-11 \\
\hline Mean intrusion errors & $2.5(2.5)$ & - & $1.0(1.3)$ & - \\
\hline Mean strategy score $(\max 12)$ & $4.9(2.6)$ & - & $8.4(2.1)$ & - \\
\hline Trails Test of Psychomotor Speed and Attention, $\mathrm{n}$ & 21 & - & 13 & Control database \\
\hline Mean age & $30.6(7.2)$ & - & $28.7(8.6)$ & \\
\hline Mean NART IQ & $105.7(9.4)$ & - & $108.4(6.9)$ & \\
\hline Mean Trails A total (seconds) & $44.5(25.5)$ & - & $28.6(7.3)$ & Average time $22-40$ \\
\hline Mean Trails B total (seconds) & $91.7(31.7)$ & - & $62.6(12.7)$ & Average time $50-75$ \\
\hline
\end{tabular}

relief by shunting (although multiple shunt revisions may also be a relevant factor), resulting in long-term and irreversible damage to developing circuits that appears not to be compensated for by the developing brain. Sobkowiak ${ }^{59}$ reported slow myelination in the congenital hydrocephalic brain as well as changes in the pre-frontal cortex on electrophysiological measures, which may be caused by damage "down-stream".

This study highlights the fact that a significant number of individuals with hydrocephalus despite having normal verbal and emotional intelligence, have a significant degree of cognitive dysfunction in many areas including memory, attention, and executive functioning. By contrast, individuals with spina bifida with no concomitant hydrocephalus do not show the same pattern of impairment. Future clinical management of the cognitive dysfunction associated with sub-groups of individuals with hydrocephalus requires routine cognitive screening in order to identify particular cognitive difficulties and restrictions that many individuals with hydrocephalus will face and to develop behavioural and pharmacological treatment strategies.

\section{ACKNOWLEDGEMENTS}

We would like to thank Romisa Ahmed for her help with data collection and Professor Simon Baron-Cohen for giving his permission and providing the materials to use the Eyes Test of Emotional Judgement. We would like to thank the Spina Bifida and Hydrocephalus Association for Hertfordshire and South Bedfordshire for their contribution to this work via two donations of $£ 2000$ each.

\section{Authors' affiliations}

J L Iddon, J D Pickard, Department of Neurosurgery, University of Cambridge, Cambridge, UK

B J Sahakian, Department of Psychiatry, University of Cambridge, Cambridge, UK

J L Iddon, D J R Morgan, Department of Academic Therapeutics, Chelsea and Westminster Hospital, London, UK

C Loveday, Department of Cognitive Neuroscience, University of Westminster, London, UK

Competing interests: none declared

\section{REFERENCES}

1 Bradbury MWB. Anatomy and physiology of cerebrospinal fluid. In: Schurr PH, Polkey CE, eds. Hydrocephalus. Oxford: Oxford University Press, 1993.

2 Thompson NM, Chapieski L, Miner ME, et al. Cognitive and motor abilities in preschool hydrocephalics. J Clin Exp Neuropsychol 1991;13:245-58.

3 Fletcher JM, Francis DJ, Thompson NM, et al. Verbal and nonverbal skill discrepancies in hydrocephalic children. J Clin Exp Neuropsychol 1992;14:593-609.

4 Fletcher JM, Bohan TP, Brandt ME, et al. Morphometric evaluation of the hydrocephalic brain: relationships with cognitive development. Child's Nerv Syst 1996;12(4): 192-9.

5 Dorman C, Laatsch LK, Hurley AD. The applicability of neuropsychological test batteries for assessment of the congenitally brain disordered. Int J Clin Neuropsychol 1985;7(2):111-7.

6 Horn DG, Lorch RF, Culatta B. Distractibility and vocabulary deficits in children with spina bifida and hydrocephalus. Dev Med Child Neurol 1985;27(6):713-20

7 Tew B. "The Cocktail Party Syndrome" in children with hydrocephalus and spina bifida. Br J Disord Commun 1979;14:447-50.

8 Cull C, Wyke MA. Memory function of children with spina bifida and shunted hydrocephalus. Dev Med Child Neurol 1984;26:177-83. 
9 Ingram TTS, Naughton JA. Paediatric and psychological aspects of cerebral palsy associated with hydrocephalus. Dev Med Child Neurol 1962;4:287-92.

10 Hagberg B, Sjorgen I. The chronic brain syndrome of infantile hydrocephalus. A follow-up study of 63 spontaneously arrested cases. Am J Dis Child 1966;112(3):189-69.

11 Taylor EM. Psychological appraisal of children with cerebral deficits. Cambridge, MA: Harvard University Press, 1961

12 Dennis M, Jacennik B, Barnes MA. The content of narrative discourse in children and adolescents after early-onset hydrocephalus and in normally developing age peers. Brain Lang 1994;46:129-65.

13 Swisher LP, Pinsker EJ. The language characteristics of hyperverbal hydrocephalic children. Dev Med Child Neurol 1971;13:746-55.

14 Fletcher JM, Barnes M, Dennis M. Language development in children with spina bifida (review). Semin Pediatr Neurol 2002;9:201-8.

15 Dennis $M$, Barnes M. Math and numeracy in young adults with spina bifida and hydrocephalus. Dev Neuropsychol 2002;21:141-55.

16 Barnes MA, Pengelly S, Dennis $M$, et al. Mathematics skill in good readers with hydrocephalus. J Int Neuropsychol Soc 2002;8:72-82.

17 Lumenta CB, Skotarczak U. Long-term follow up of 233 patients with congenital hydrocephalus. Child's Nerv Syst 1995;11(3):173-5.

18 Dise LE, Lohr ME. Examination of deficits in conceptual reasoning abilities associated with spina bifida. Am J Phys Med Rehabil 1998;77:247-51.

19 Snow JH, Prince M, Souheaver G, et al. Neuropsychological patterns of adolescents and young adults with spina bifida. Arch Clin Neuropsychol 1994;9(3):277-87.

20 Culatta B, Young C. Linguistic performance as a function of abstract task demands in children with spina bifida. Dev Med Child Neurol 1992;34(5):434-40

21 Tew BJ, Laurence KM. The clinical and psychological characteristics of children with 'cocktail party' syndrome. Z Kinderchir 1975;28:360-7.

22 Appleton PL, Minchom PE, Ellis NC, et al. The self-concept of young people with spina bifida: a population-based study. Dev Med Child Neurol 1994;36:198-215.

23 Appleton PL, Ellis MC, Minchom PE, et al. Depressive symptoms and selfconcept in young people with spina bifida. J Paediatr Psychol 1997;22:707-22.

24 Hazlett RA. Self perceptions of preschool children with spina bifida. J Paediatr Nurs 1997;12:130-1

25 Minchom PE, Ellis NC, Appleton PL, et al. Impact of functional severity on self concept in young people with spina bifida. Arch Dis Child 1995;73:48-52.

26 Hagberg B. The sequelae of spontaneously arrested infantile hydrocephalus. Dev Med Child Neurol 1962;4:583-7.

27 Miller E, Sethi L. The effects of hydrocephalus perception. Dev Med Child Neurol 1971;13(suppl 25):77-81.

28 Taylor EM. Psychological appraisal of children with cerebral deficits. Cambridge, MA: Harvard University Press, 1961

29 Simpson D, Hemmer R. Social aspects of hydrocephalus. In: Schurr PH Polkey CE, eds. Hydrocephalus. Oxford: Oxford University Press, 1993.

30 Malm J, Kristensen B, Karlsson T, et al. A predictive value of cerebrospinal fluid dynamic tests in patients with the idiopathic adult hydrocephalus syndrome. Arch Neurol 1995;52:783-9.

$31 \mathrm{Chen} \mathrm{IH}$, Huang $\mathrm{Cl}$, Liu $\mathrm{HC}$, et al. Effectiveness of shunting in patients with normal pressure hydrocephalus predicted by temporary, controlled resistance continuous lumbar drainage: a pilot study. I Neurol Neurosurg Psychiatry 1994;57:1430-2.

32 Raftopoulos C, Deleval J, Chaskis C, et al. Cognitive recovery in idiopathic normal pressure hydrocephalus: a prospective study. Neurosurgery 1994;35:397-405.

33 Stambrook M, Cardosa ER, Hawryluk GA, et al. Neuropsychological changes following the neurosurgical treatment of normal pressure hydrocephalus. Arch Clin Neuropsychol 1988;3:323-30.
34 Iddon JL, Pickard JD, Cross JJL, et al. Specific patterns of cognitive impairment in patients with idiopathic 'normal pressure' hydrocephalus and Alzheimer's disease: a pilot study. J Neurol Neurosurg Psychiatry 1999;67:723-31.

35 Cummings JL. Introduction. In: Cummings JL, ed. Subcortical dementia. New York: Oxford University Press, 1990, chapter 1.

36 Thomsen AM, Borgeson SE, Bruhn P, et al. Prognosis of dementia in normal pressure hydrocephalus after a shunt operation. Ann Neurol 1986;20:304-10

37 Torkelson RD, Leibrock LG, Gustavson JL, et al. Neurological and neuropsychological effects of cerebral spinal fluid shunting in children with assumed arrested ("normal pressure") hydrocephalus. J Neurol Neurosurg Psychiatry 1986;48:799-806.

38 Caltagirone C, Gainotti G, Masullo C, et al. Neurophysiological study of normal pressure hydrocephalus. Acta Psychiatr Scand 1982:65(2):93-100.

39 Gustafson L, Hagberg B. Recovery in hydrocephalic dementia after shunt operation. J Neurol Neurosurg Psychiatry 1978;41:10.

40 Morgan DJR, Blackburn M, Bax M. Adults with spina bifida and/or hydrocephalus. Postgrad Med J 1995;71:17-21.

41 Nelson HE. National Adult Reading Test. Test manual. Windsor, UK: NFERNELSON, 1982.

42 Beck AT. Depression: causes and treatment. Philadelphia, PA: University of Pennsylvania Press, 1970.

43 Cockrell JR, Folstein MF. Mini-Mental State Examination (MMSE). Psychopharmacol Bull, 1988;24:689-92.

44 Baron-Cohen S, Jolliffe T, Mortimore C, et al. Another advanced test of theory of mind: evidence from very high functioning adults with autism or Asperger syndrome. J Child Psychol Psychiatry 1997;38:813-22.

45 Benton AL, Hamshire K de S. Multilingual Aphasia Examination. lowa City, IA: University of lowa, 1976.

46 Owen AM, Downes JD, Sakakian BJ, et al. Planning and spatial working memory following frontal lobe lesions in man. Neuropsychologia 1990;28:1021-34.

47 Owen AM, Sahakian BJ, Semple J, et al. Visuo-spatial short-term recognition memory and learning after temporal lobe excisions or amygdalohippocampectomy in man. Neuropsychologia 1995;33:1-24.

48 Milner B. Interhemispheric differences in the localisation of psychological processes in man. Br Med Bull 1971:27:272-77.

49 Downes JJ, Roberts AC, Sahakian BJ, et al. Impaired extra-dimensional shift performance in medicated and unmedicated Parkinson's disease: evidence for a specific attentional dysfunction. Neuropsychologia 1989;27:1239-343.

50 Owen AM, James M, Leigh PN, et al. Fronto-striatal cognitive deficits at different stages of Parkinson's disease. Brain 1992;115:1727-51.

51 Spreen O, Strauss E. A compendium of neuropsychological tests. New York: Oxford University Press, 1998.

52 Benedict RHB, Schretlen D, Groninger L, et al. Hopkins Verbal Learning TestRevised: Normative data and analysis of inter-form and test-retest reliability. Clin Neuropsychol 1998;12:43-55

53 Landry S. Goal-directed behaviour and perception of self-competence in children with spina bifida. J Pediatric Psychol 1993;18:389-96.

54 Ineichen R. Towards co-ordinated care of spina bifida children. Soc Work Today 1973;4:321-4.

55 Fletcher JM, Brookshire BL, Landry SH, et al. Behavioural adjustment of children with hydrocephalus: relationships with etiology, neurological and family status. J Pediatr Psychol 1995;20:109-25.

56 Campbell S. Early prenatal diagnosis of neural tube defects by ultrasound. Clin Obstet Gynecol 1977;20:351-9.

57 Spaulding BR, Morgan SB. Spina bifida and their parents: a population prone to family dysfunction. J Pediatr Psychol 1986;1 1:359-74.

58 Fishman R. Normal pressure hydrocephalus and arthritis. N Engl J Med 1985;312:1255-6.

59 Sobkowiak CA. Effect of hydrocephalus on neuronal migration and maturation. Eur J Pediatric Surg 1992;2(suppl 1):7-11. 